\title{
A flexible approach for engineering macrocyclic high performance pentagonal bipyramidal Dy(III) single-ion magnets'
}

\author{
Angelos B. Canaj, ${ }^{\text {a }}$ Sourav Dey, ${ }^{\mathrm{b}}$ Claire Wilson, ${ }^{\mathrm{a}}$ Oscar Cespedes, ${ }^{\mathrm{c}}$ Gopalan Rajaraman* ${ }^{\mathrm{b}}$ and Mark \\ Murrie* $*^{a}$
}

\begin{abstract}
A strong uniaxial ligand field generated by the $\mathrm{Ph}_{3} \mathrm{SiO}^{-}$ligand combined with the weak equatorial field of the macrocyclic ligand $\mathrm{L}^{\mathrm{N} 5}$, generates $\left[\mathrm{Dy} \mathrm{I}^{\mathrm{III}}\left(\mathrm{L}^{\mathrm{N5}}\right)\left(\mathrm{Ph}_{3} \mathrm{SiO}\right)_{2}\right]^{+}$, a pentagonal bipyramidal Dy(III) Single-Molecule Magnet with a high anisotropy barrier of $1108 \mathrm{~K}$, and hysteresis loops open up to $14 \mathrm{~K}$. Based on our synthetic blueprint, we use $a b$ initio calculations to predict changes to the macrocycle to increase the barrier to $\sim 1800 \mathrm{~K}$.
\end{abstract}

Molecular systems which display the ability to retain magnetisation, in the absence of an external magnetic field, resulting in the appearance of magnetic memory of molecular origin, are known as Single-Molecule Magnets (SMMs). ${ }^{1}$

Lanthanide-based SMMs are often associated with large magnetic moments and large magnetic anisotropy. In $4 f$ SMMs, the energy barrier to reorientation of the magnetisation $\left(U_{\text {eff }}\right)$ is strongly determined by the control of the coordination environment at the level of a single metal ion. ${ }^{2}$ Specifically, the use of the Dy(III) ion in targeted coordination environments that promote strong uniaxial symmetry stabilizes the largest $m_{\jmath}= \pm 15 / 2$ ground state and gives a large separation from the excited $m_{\mathrm{J}}$ states. $^{2}$ Monometallic complexes with axial symmetry such as square antiprismatic, $^{3}$ trigonal bipyramidal, ${ }^{4}$ pentagonal bipyramidal, ${ }^{5,6}$ and hexagonal bipyramidal, ${ }^{7,8}$ are an effective way to favour slower relaxation of the magnetisation. Furthermore, sandwich type ligands (e.g. cyclopentadienyl (Cp) anionic ligands), have generated organometallic compounds with impressive blocking temperatures showing coercivity up to $30 \mathrm{~K},{ }^{9} 48 \mathrm{~K},{ }^{10} 55 \mathrm{~K}^{11} 60 \mathrm{~K},{ }^{12} 66 \mathrm{~K}^{13}$ and $80 \mathrm{~K}^{14}$ Additionally, of particular interest are the endohedral metallofullerenes (EMFS) with lanthanide ions. ${ }^{15}$

We have explored how the ligand electronics can tune SMM properties ${ }^{5,7,16,17}$ and recently first introduced a blueprint for engineering strong uniaxial magnetic anisotropy for Dy(III) ions in a hexagonal bipyramidal geometry, ${ }^{7}$ boosting the magnetisation reversal barrier from $\sim 50 \mathrm{~K}^{18}$ to $\sim 1100 \mathrm{~K}$, by using the macrocyclic ligand $\mathrm{L}^{\mathrm{N} 6}$ (Scheme 1 left). Implementing further the flexibility of our synthetic approach towards the engineering of new quasi- $D_{\text {nh }}$ systems, we herein demonstrate the isolation of a new Single-lon Magnet (SIM) with pentagonal bipyramidal geometry, [Dy $\left.y^{\prime \prime \prime}\left(\mathrm{L}^{\mathrm{N5}}\right)\left(\mathrm{Ph}_{3} \mathrm{SiO}\right)_{2}\right]\left(\mathrm{BPh}_{4}\right)$ . $\mathrm{CH}_{2} \mathrm{Cl}_{2}$ (1). Compound 1 shows out-of-phase peaks in the ac susceptibility up to $80 \mathrm{~K}$ under zero dc field, a high magnetization reversal barrier of $1108 \mathrm{~K}$ and hysteresis, $M(\mathrm{H})$, loops open up to $14 \mathrm{~K}$, measured at an average sweep rate of $0.01 \mathrm{~T} / \mathrm{s}$ (See Table S1). In our carefully designed step-by-step synthetic approach we first targeted the formation of a weak N5-pentagonal plane by employing the macrocyclic $\mathrm{L}^{\mathrm{N} 5}$ ligand (Scheme 1, right), unused in $4 f$ chemistry, formed from 2,6- diacetylpyridine and N,N'-Bis-(3-aminopropyl)ethylendiamine. ${ }^{19}$ We then used the anion of triphenylsilanol, $\mathrm{Ph}_{3} \mathrm{SiO}^{-}$, as stronger anionic donors at both axial positions to generate the pentagonal bipyramidal architecture (Fig. 1).

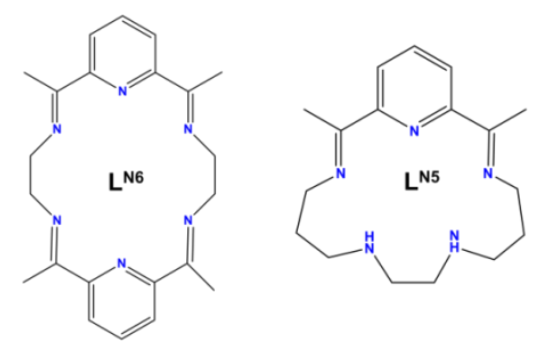

Scheme 1. The macrocyclic ligand $\mathbf{L}^{\mathrm{N} 6}$ (left) $^{7}$ and $\mathbf{L}^{\mathrm{N} 5}$ (right, $\mathbf{L}^{\mathrm{N} 5}=$ N5-pentagonal plane from the neutral Schiff base ligand formed from 2,6-diacetylpyridine and N,N'-Bis-(3aminopropyl)-ethylendiamine).

Importantly, our synthetic strategy offers vast synthetic flexibility for carefully engineering the equatorial crystal field in order to further improve the relaxation dynamics and to target the isolation of new quasi- $D_{\text {nh }}$ systems with enhanced magnetic anisotropy. In a quest to identify new promising directions towards high temperature SMMs we investigate the new in-silico model 1-05 (vide infra), inspired by 1. From our systematic study, we find that the proposed in-silico model is extremely promising as a new target system and has the potential to show improved SMM properties, with the magnetisation reversal barrier boosted up to $c a .1800 \mathrm{~K}$ (vide infra).

Compound 1 (Fig. 1) crystallises in the triclinic space group $P \overline{1}$ (Table S2) with the asymmetric unit containing two crystallographically independent molecules with a Dy...Dy distance of $11.667 \AA$. Both Dy(III) centres are found in an axially compressed pentagonal bipyramidal geometry, as confirmed via SHAPE analysis (see Table S4 and Fig S3). ${ }^{20}$ Two $\mathrm{Ph}_{3} \mathrm{SiO}^{-}$ligands occupy the axial positions providing the shortest axial Dy-O bond lengths of 2.157(3) $\AA$ and 2.136(4) $\AA$ for Dy1A and 2.161(4) $\AA$ and 2.158(4) $\AA$ for Dy1B (See Table S3 and Fig S2). In addition, the axial O-Dy-O angle is $176.54(15)^{\circ}$ and $173.13(15)^{\circ}$ for Dy $1 \mathrm{~A}$ and $\mathrm{Dy} 1 \mathrm{~B}$, respectively. In the equatorial plane of the $L^{\mathrm{N} 5}$ ligand (Fig. S2) the Dy-N bonds fall in the range of 2.400(5)-2.570(5) $\AA$ for Dy1A and 2.457(5)2.564(5) A for Dy1B (Table S3).

The static dc magnetic susceptibility and magnetization measurements for complex 1 are shown in the ESI (Fig. S4-S5). Upon cooling the $\chi_{M} T$ profile of 1 decreases steadily from the room temperature value of $14.1 \mathrm{~cm}^{3} \mathrm{~mol}^{-1} \mathrm{~K}$ to a value of 13.05 $\mathrm{cm}^{3} \mathrm{~mol}^{-1} \mathrm{~K}$ at $10 \mathrm{~K}$ followed by a sharp drop below $10 \mathrm{~K}$ (Fig. 
S4). The field-cooled (FC) and zero-field cooled (ZFC) magnetic susceptibility (Fig. S6) diverge at $7 \mathrm{~K}$ for 1 with the maximum observed at $\sim 5 \mathrm{~K}$, indicative of a magnetic blocking temperature, $T_{\mathrm{B}}{ }^{21}$ The magnetic hysteresis measurements, $M(H)$ loops, performed on a microcrystalline powder sample of 1 remain open up to $14 \mathrm{~K}$, measured at a sweep rate of 0.01 T/s (Fig. 2 and Fig. S7). The characteristic waist-restricted shape of the loops is strongly affected by the faster relaxation around zero field, due to the presence of unsuppressed Quantum Tunnelling of the Magnetisation (QTM). ${ }^{3}$

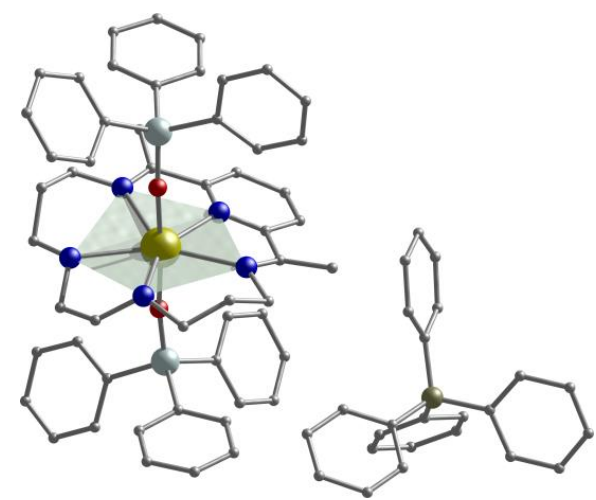

Figure 1. Molecular structure of 1 with two $\mathrm{Ph}_{3} \mathrm{SiO}^{-}$axial ligands and the polydentate ligand $\mathbf{L}^{\mathbf{N 5}}$ in the equatorial plane, highlighted in green. Dy, gold; $\mathrm{O}$, red; $\mathrm{N}$, blue; $\mathrm{Si}$, light turquoise; C, gray; B, dark yellow. Hydrogen atoms, solvent molecules and disorder components are omitted for clarity.

around zero field, due to the presence of unsuppressed Quantum Tunnelling of the Magnetisation (QTM). ${ }^{3}$

Alternating current (ac) susceptibility measurements were performed in order to investigate the magnetic relaxation in $\mathbf{1}$ (Fig. 3 and Fig. S8-S11). Under zero dc field, the out-of-phase $\chi_{\mathrm{M}}{ }^{\prime \prime}$ susceptibility data exhibit well-defined maxima, clearly observable at temperatures up to $80 \mathrm{~K}$ (Fig. 3), indicative of slow magnetic relaxation and a high magnetisation reversal barrier. The magnetisation relaxation times, $\tau$, were extracted by fitting the Argand plots of $\chi_{\mathrm{M}}{ }^{\prime \prime}$ vs. $\chi_{\mathrm{M}}{ }^{\prime}$ using the generalized Debye model (Fig. S11). ${ }^{22}$ The $\alpha$-parameters found are in the range of 0.17-0.43 (2-80 K) showing a relatively wide distribution of relaxation times. The $\tau^{-1}$ vs. $T$ data were fitted using the equation $\tau^{-1}=\tau_{\mathrm{QTM}}{ }^{-1}+\mathrm{CT}^{\mathrm{n}}+\tau_{0}{ }^{-1}$ $\exp \left(-U_{\text {eff }} / T\right)$, in which $C$ and $n$ are the parameters of the Raman process and $\tau_{\text {QTM }}$ is the rate of QTM. ${ }^{3,21}$ The best fit gives an energy barrier of $U_{\text {eff }}=1108 \mathrm{~K}, \tau_{0}=1.56 \times 10^{-11} \mathrm{~s}, n=2.05, C=0.03 \mathrm{~K}^{-\mathrm{n}} \mathrm{s}^{-1}$, $\tau_{\text {QTM }}=0.5 \mathrm{~s}$, under zero dc field (Fig. S12). The values of $\tau_{0}, C$ and $n$ are within the commonly observed range for Dy(III) SMMs. ${ }^{3}$ The exponent $n$ of the Raman process has a smaller value than expected for a Kramers ions (i.e., $n=9$ ) suggesting the presence of Raman processes involving optical acoustic phonons. ${ }^{22}$

$A b$ initio calculations on $\mathbf{1}$, using the CASSCF/RASSISO/SINGLE_ANISO approach implemented in MOLCAS 8.227 (see $\mathrm{ESI}+$ ), ${ }^{23}$ reveal that the eight Kramers Doublets (KDs) span an energy range of $\sim 1520 \mathrm{~K}$. Inspection of the calculated $g$-tensors (Table S5) show a highly anisotropic ground state $\left(m_{\mathrm{J}}= \pm 15 / 2\right)$ with strong axiality $\left(g_{z z}=19.979, g_{x x,}, g_{y y}=0.001\right.$ for Dy1A and $g_{z z}=19.984, g_{x x}$ $\mathrm{g}_{\mathrm{yy}}=0.000$ for Dy1B). The main anisotropy axis in $\mathbf{1}$ is nearly collinear with the shortest O-Dy-O bonds, stabilised by the stronger donor
$\mathrm{Ph}_{3} \mathrm{SiO}^{-}$ligands located above and below the equatorial plane of the $\mathrm{L}^{\mathrm{N} 5}$ ligand (Fig. 1 and Fig. S13).

The first excited state $\left(m_{\mathrm{J}}= \pm 13 / 2\right.$, located at $\sim 600 \mathrm{~K}(594 \mathrm{~K}$ for Dy $1 \mathrm{~A}$ and 602 for Dy $1 B)$ and the second excited state $\left(m_{J}= \pm 11 / 2\right)$ located at $1040 \mathrm{~K}$ (1033 for Dy1A and 1040 for Dy1B) are also axial in nature (Fig. 4 Upper, Fig. S14 and Table S5). The maximum calculated relaxation barrier, $U_{\text {cal, }}$ for compound $\mathbf{1}$ is estimated at $\sim$ $1040 \mathrm{~K}$; in excellent agreement with the experimentally determined magnetisation reversal barrier $\left(U_{\text {eff }}\right)$ of $1108 \mathrm{~K}$ found in zero dc field.

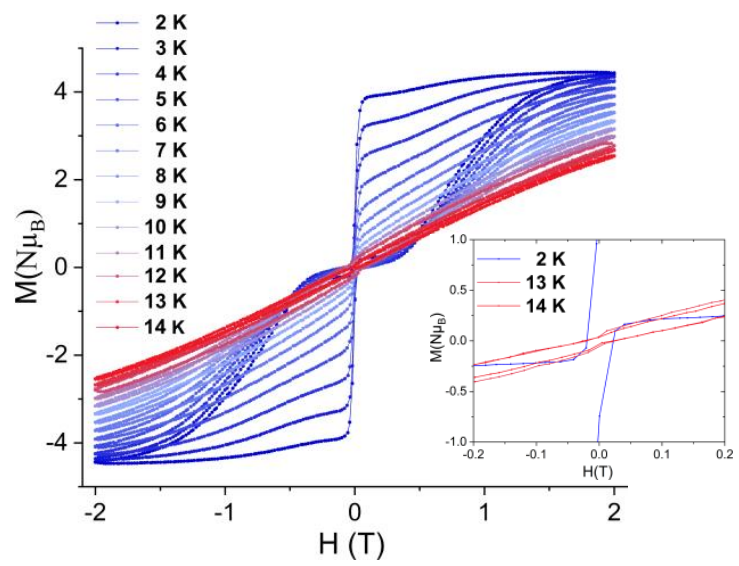

Figure 2. Powder magnetic hysteresis measurements for $\mathbf{1}$ with an average sweep rate of $0.01 \mathrm{~T} / \mathrm{s}$. Inset: $M(\mathrm{H})$ loops around zero field region open up to $14 \mathrm{~K}$.
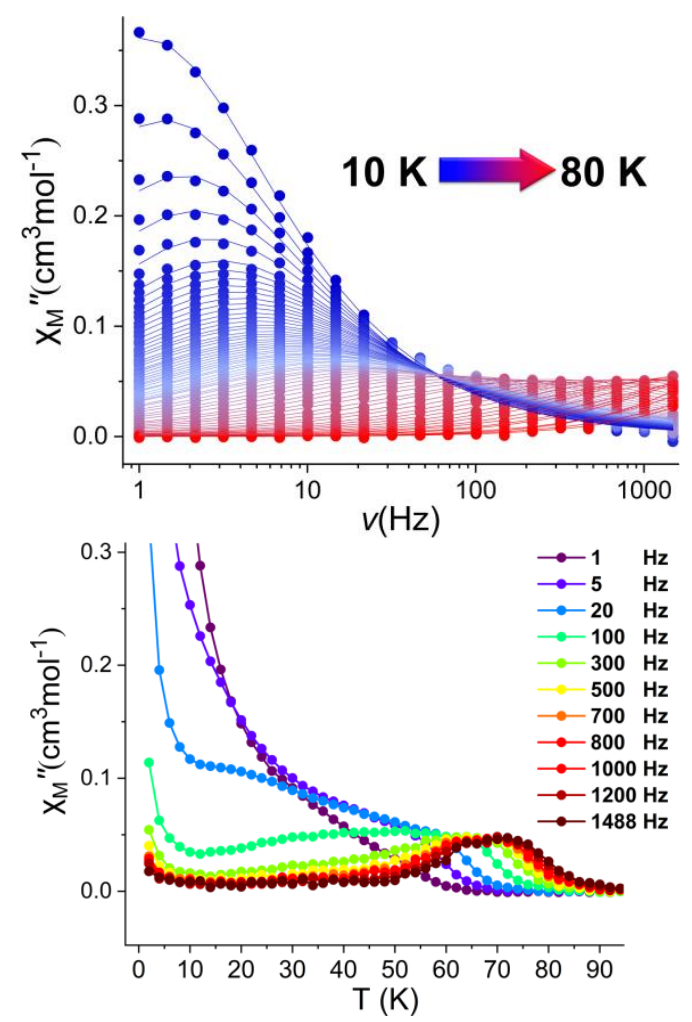

Figure 3. (Upper) Plots of $\chi_{\mathrm{M}}{ }^{\prime \prime}(v)$ in zero applied dc field in the temperature range of $10-80 \mathrm{~K}$ for 1 . (Lower) Plots of $\chi_{\mathrm{M}}{ }^{\prime \prime}(\mathrm{T})$ in zero applied dc field.

Significantly, the ability to find promising candidate systems that have the potential to show improved SMM properties and could be 
targeted by experimental chemists is of key importance. Using 1 as a blueprint we have created the in-silico model system 1-05. In the new model system we examine how changes in the first coordination sphere of $\mathbf{1}$, at the equatorial positions (Fig. S15), affect the magnetic anisotropy and have the potential to improve the performance of SMMs, boosting the magnetisation reversal barrier to new heights ( $c a .1800 \mathrm{~K}$ ). In the model system 1-05 we have maintained the same coordination environment at the axial positions as in 1 (i.e., the axial $\mathrm{Ph}_{3} \mathrm{SiO}^{-}$ligands), but the equatorial ligand $\mathrm{L}^{\mathrm{N} 5}$ has been modified in-silico to the 16 -crown-5 ligand (i.e., the closest candidate of the crown ether family to the $L^{\mathrm{N5}}$ ) (Fig. S15). We have employed the crown ether ligand in the equatorial plane of our model system because of its neutral nature, long metal-ligand distances, the popularity of crown ether ligands in $4 f$ chemistry ${ }^{24}$ and to compare it with the nitrogen based macrocyclic ligand, $\mathrm{L}^{\mathrm{N} 5}$, used in 1. In the model system 1-05 the strongly axial excited states are higher in energy than that of 1 (Table S6). In addition, the transverse components for model system 1-05 are weaker giving lower $g_{\mathrm{xx}} / g_{\mathrm{yy}}$ values (Table S6). Furthermore, using the CASSCF wavefunction, the computed Loprop ${ }^{26}$ charges for 1 reveal larger negative charges at the secondary amine - $\mathrm{NH}$ - groups of the equatorial L ${ }^{\mathrm{N} 5}$ ligand (Fig. S16), compared to the lower charges generated by the oxygen atoms of the crown ether ligand of 1-05 (Fig. S17). The QTM probabilities calculated for the first three KDs $\left(0.45 \times 10^{-4}, 0.49 \times 10^{-2}, 0.68 \times 10^{-1} \mu_{\mathrm{B}}\right.$, respectively) are lower compared to 1 with the

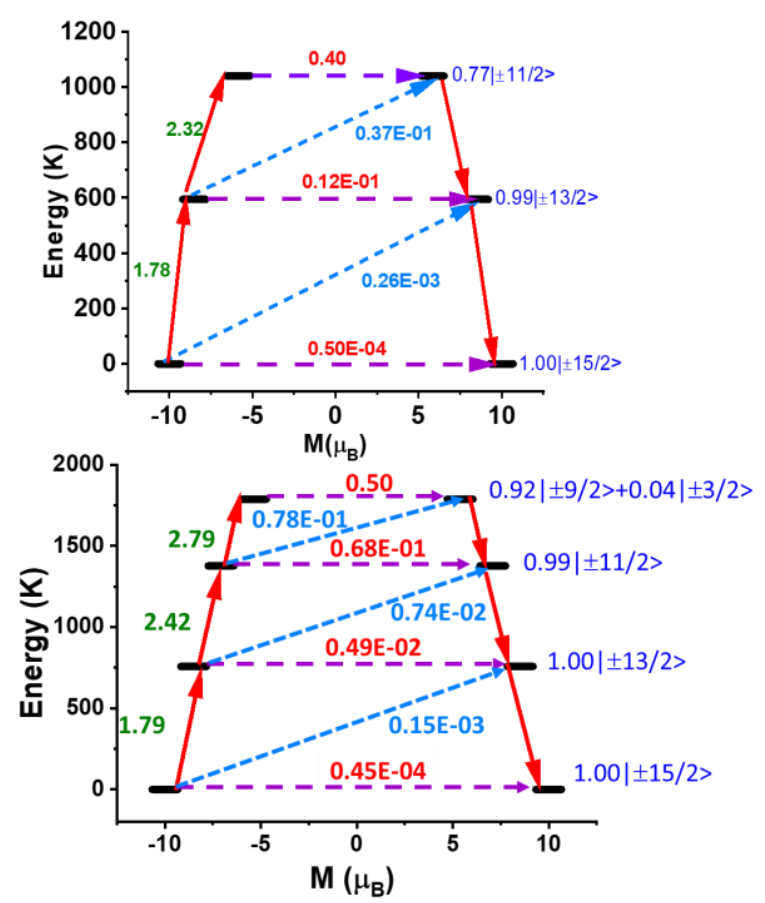

Figure 4. $A b$ initio calculated relaxation dynamics for 1 (Upper, shown for Dy1B) and 1-05 (Lower). The black line indicates the KDs as a function of magnetic moments. The violet dashed arrow represents QTM (QTM = quantum tunnelling of the magnetisation) via the ground state and TA-QTM (TA-QTM = thermally assisted QTM) via excited states. The blue dashed arrow indicates possible Orbach processes. The red arrows indicate the mechanism of magnetic relaxation. The numbers above each arrow represent corresponding transverse matrix elements for the transition magnetic moments. ${ }^{25}$ magnetization relaxing via the fourth KD giving a calculated magnetization reversal barrier of $1788 \mathrm{~K}$ (Fig. 4, lower). The ratio between the axial $\mathrm{B}_{2}{ }^{0}$ parameter and the corresponding non-axial crystal field parameters also increases $1<1-05$ (Table S7) supporting the increase of $U_{\text {cal }}$ from 1 ( $\left.1040 \mathrm{~K}\right)$ to 1-05 ( $\left.1788 \mathrm{~K}\right)$. In conclusion, we report $\left[\mathrm{Dy}{ }^{\prime \prime \prime}\left(\mathrm{L}^{\mathrm{N} 5}\right)\left(\mathrm{Ph}_{3} \mathrm{SiO}\right)_{2}\right]\left(\mathrm{BPh}_{4}\right) \mathrm{CH}_{2} \mathrm{Cl}_{2}$ (1) using the macrocyclic ligand $\mathrm{L}^{\mathrm{N} 5}$, which is a strongly axial $\mathrm{Dy}(\mathrm{III})$ single-ion magnet in a pentagonal bipyramidal geometry showing out-ofphase peaks up to $80 \mathrm{~K}$ under zero field, a high anisotropy barrier of $1108 \mathrm{~K}$, and hysteresis loops open up to $14 \mathrm{~K}$ (@ $0.01 \mathrm{~T} / \mathrm{s}$ ). This novel compound was engineered following our flexible synthetic approach where five long Dy-N bonds are formed by the macrocyclic ligand $\mathrm{L}^{\mathrm{N} 5}$, while two strong donor $\mathrm{Ph}_{3} \mathrm{SiO}^{-}$ligands are used for the axial positions, creating the short O-Dy-O bonds, highlighting the vast synthetic scope for macrocyclic engineering of magnetic anisotropy. Furthermore, we show a promising direction towards a new pentagonal bipyramidal family by carefully tuning the equatorial ligand field of the macrocycle and synthetic efforts are underway with both $\mathrm{O}$ - and S-donors towards this goal.

We thank EPSRC UK (EP/N01331X/1, EP/M000923/1) for funding. S.D thanks UGC for an SRF fellowship. G.R thanks DST/SERB for funding (CRG/2018/000430; DST/SJF/CSA03/2018-10; SB/SJF/2019-20/12).

\section{Conflicts of interest}

There are no conflicts to declare.

\section{Notes and references}

1 S. M. J. Aubin, M. W. Wemple, D. M. Adams, H.-L. Tsai, G. Christou and D. N. Hendrickson, J. Am. Chem. Soc., 1996, 118, 7746; R. Sessoli, H. L. Tsai, A. R. Schake, S. Wang, J. B. Vincent, K. Folting, D. Gatteschi, G. Christou and D. N. Hendrickson, J. Am. Chem. Soc., 1993, 115, 1804; C. J. Milios, A. Vinslava, W. Wernsdorfer, S. Moggach, S. Parsons, S. P. Perlepes, G. Christou, E. K. Brechin, J. Am. Chem. Soc., 2007, 129, 2754.

2 A. Castro-Alvarez, Y. Gil, L. Llanos and D. Aravena, Inorg. Chem. Front., 2020, DOI:10.1039/D0QI00487A; M. J. Heras Ojea, L. H. C. Maddock and R. A. Layfield, in, Lanthanide Organometallics as Single-Molecule Magnets, Vol. 64, Springer, New York, NY 2019; F. -S. Guo and R. A. Layfield, Acc. Chem. Res., 2018, 51, 1880; M. Feng and M. -L. Tong, Chem. Eur. J., 2018, 24, 7574; A. K. Bar, P. Kalita, M. K. Singh, G. Rajaraman and V. Chandrasekhar, Coord. Chem. Rev., 2018, 367, 163.

3 S. Bala, G.-Z. Huang, Z.-Y. Ruan, S.-G. Wu, Y. Liu, L.-F. Wang, J.-L. Liu and M.-L. Tong, Chem. Commun., 2019, 55, 9939; J. Wu, J. Jung, P. Zhang, H. Zhang, J. Tang and B. Le Guennic, Chem. Sci., 2016, 7, 3632; K. Katoh, S. Yamashita, N. Yasuda, Y. Kitagawa, B. K. Breedlove, Y. Nakazawa and M. Yamashita, Angew. Chem. Int. Ed., 2018, 57, 9262.

4 P. Zhang, L. Zhang, C. Wang, S. Xue, S.-Y. Lin and J. Tang, J. Am. Chem. Soc. 2014, 136, 4484; K. L. M. Harriman, J. L. Brosmer, L. Ungur, P. L. Diaconescu and M. Murugesu, J. Am. Chem. Soc., 2017, 139, 1420; S.-M. Chen, Y.-Q. Zhang, J. Xiong, B.-W. Wang and S. Gao, Inorg. Chem. 2020, 59, 5835.

5 A. B. Canaj, M. K. Singh, C. Wilson, G. Rajaraman and M. Murrie, Chem. Commun., 2018, 54, 8273.

6 Y. -C. Chen, J.-L. Liu, L. Ungur, J. Liu, Q.-W. Li, L.-F. Wang, Z.-P. Ni, L. F. Chibotaru, X. -M. Chen and M. -L. Tong, J. Am. Chem. 
Soc., 2016, 138, 2829; Y. -S. Ding, N. F. Chilton, R. E. P. Winpenny and Y. -Z. Zheng, Angew. Chem. Int. Ed., 2016, 55, 16071; J. Liu, Y.-C. Chen, J.-L. Liu, V. Vieru, L. Ungur, J. -H. Jia, L. F. Chibotaru, Y. Lan, W. Wernsdorfer, S. Gao, X. -M. Chen and M. -L. Tong, J. Am. Chem. Soc., 2016, 138, 5441; Y. Ma, Y.-Q. Zhai, Y.-S. Ding, T. Han and Y. Z. Zheng, Chem. Commun., 2020, 56, 3979; J. L. Liu, Y. C. Chen, Y. Z. Zheng, W. Q. Lin, L. Ungur, W. Wernsdorfer, L. F. Chibotaru and M. L. Tong, Chem. Sci., 2013, 4, 3310; Y.-S. Ding, T. Han, Y.-Q. Zhai, D. Reta, N. F. Chilton, R. E.P. Winpenny and Y.-Z. Zheng, Chem. Eur.J., 2020, 26, 5893; S. K. Gupta, T. Rajeshkumar, G. Rajaraman and R. Murugavel, Chem. Sci., 2016, 7, 5181.

7 A. B. Canaj, S. Dey, E. R. Marti, C. Wilson, G. Rajaraman and M. Murrie, Angew. Chem. Int. Ed., 2019, 58, 14146; A. B. Canaj, S. Dey, E. R. Marti, C. Wilson, G. Rajaraman and M. Murrie, Angew. Chem. 2019, 131, 14284;

8 Z.-H. Li, Y.-Q. Zhai, W.-P. Chen, Y.-S. Ding and Y.-Z. Zheng, Chem. Eur. J., 2019, 25, 16219.

9 S. Demir, M I. Gonzalez, L. E. Darago, W. J. Evans and J R. Long, Nat Commun, 2017, 8, 2144.

10 P. Evans, D. Reta, G. F. Whitehead, N. F. Chilton and D. P. Mills, J. Am. Chem. Soc., 2019, 141, 19935.

11 C. Gould, K. R. McClain, J. Yu, T. J Groshens, F. Furche, B. G. Harvey and J. R. Long, J. Am. Chem. Soc. 2019, 141, 12967.

12 A. P. Goodwin, F. Ortu, D. Reta, N. F. Chilton and D. P. Mills, Nature, 2017, 548, 439; F. -S. Guo, B. M. Day, Y.-C. Chen, M. L. Tong, A. Mansikkamaki and R. A. Layfield, Angew. Chem. Int. Ed. 2017, 56, 11445;

13 K. R. McClain, C. A. Gould, K. Chakarawet, S. J. Teat, T. J. Groshens, J. R. Long and B. G. Harvey, Chem. Sci., 2018, 9, 8492.

14 F.-S. Guo, B. M. Day, Y.-C. Chen, M.-L. Tong, A. Mansikkamäki and R. A. Layfield, Science, 2018, 362, 1400.

15 L. Spree and A. A. Popov Dalton Trans., 2019, 48, 2861; W. Yang, G. Velkos, F. Liu, S. M. Sudarkova, Y. Wang, J. Zhuang, H. Zhang, X. Li, X. Zhang, B. Büchner, S. M. Avdoshenko, A. A. Popov and N. Chen, Adv. Sci. 2019, 1901352; G. Velkos, W. Yang, Y.-R. Yao, S. M. Sudarkova, X. Liu, B. Büchner, S. M. Avdoshenko, N. Chen and A. A. Popov, Chem. Sci., 2020, 11, 4766; Y. Wang, J. Xiong, J. Su, Z. Hu, F. Ma, R. Sun, X. Tan, H.-Ling Sun, B.-Wu Wang, Z. Shi and S. Gao, Nanoscale, 2020, 12, 11130.

16 A. B. Canaj, M. K. Singh, E. R. Marti, M. Damjanović, C. Wilson, O. Céspedes, W. Wernsdorfer, G. Rajaraman and M. Murrie, Chem. Commun. 2019, 55, 5950.

17 A. B. Canaj, S. Dey, C. Wilson, O. Cespedes, G. Rajaraman and M. Murrie Chem. Commun., 2020, 56, 1533.

18 J. Li, S. Gomez-Coca, B. S. Dolinar, L. Yang, F. Yu, M. Kong, Y.Q. Zhang, Y. Song, K. R. Dunbar, Inorg. Chem. 2019, 58, 2610; Q. -W. Li, R.-C. Wan, Y. -C. Chen, J .-L. Liu, L.-F. Wang, J.-H. Jia, N. F. Chilton, M. -L. Tong, Chem. Commun. 2016, 52, 13365; W. Zhao, H. Cui, X.-Y. Chen, G. Yi, L. Chen, A. Yuan, C.L. Luo, Dalton Trans. 2019, 48, 5621

19 S. M. Nelson, S. G. McFall, M. G. B. Drew, A. H. Bin Othman and N. B. Mason, J. Chem. Soc., Chem. Commun., 1977, 167.

20 M. Pinskya and D. Avnir, Inorg. Chem., 1998, 37, 5575; D. Casanova, P. Alemany, J. M. Bofill and S. Alvarez, Chem. Eur. J., 2003, 9, 1281.

21 D. Gatteschi, R. Sessoli, and J. Villain, Molecular Nanomagnets; Oxford University Press: Oxford, 2006.

22 K. N. Shrivastava, Phys. Status Solidi B, 1983, 117, 437; S. Q. Wu, Y. Miyazaki, M. Nakano, S. Q. Su, Z. S. Yao, H. Z. Kou and O. Sato, Chem. Eur. J., 2017, 23,10028; A. Singh and K. N. Shrivastava, Phys. Status Solidi B 1979, 95, 273; A. Chiesa, F. Cugini, R. Hussain, E. Macaluso, G. Allodi, E. Garlatti, M. Giansiracusa, C. A. P. Goodwin, F. Ortu, D. Reta, J. M. Skelton, T. Guidi, P. Santini, M. Solzi, R. De Renzi, D. P. Mills, N. F. Chilton and S. Carretta, Phys. Rev. B, 2020, 101, 174402.

23 A. A. Granovsky, J. Chem. Phys., 2011, 134, 214113; F. Aquilante, J. Autschbach, R. K. Carlson, L. F. Chibotaru, M. G.
Delcey, L. De Vico, I. Fdez Galvan, N. Ferre, L. M. Frutos and L. Gagliardi, et al., J. Comput. Chem., 2016, 37, 506; L. F. Chibotarua and L. Ungur, J. Chem. Phys., 2012, 137, 064112.

24 Y. Gil, L. Llanos, P. Cancino, P. Fuentealba, A. Vega, E. Spodine and D. Aravena, J. Phys. Chem. C 2020, 124, 5308; E. L. Gavey, M. Al Hareri, J. Regier, L. D. Carlos, R. A. S. Ferreira, F. S. Razavi, J. M. Rawson and M. P. Pilkington, J. Mater. Chem. C 2015, 3, 7738; Y.-S., Ding, T. Han, H. Yue-Qiao, X. Minwei, Y. Sen and Z. Yan-Zheng, Inorg. Chem. Front. 2016, 3, 798; E. Rousset, M. Piccardo, M. E. Boulon, R. W. Gable, A Soncini, L. Sorace and C. Boskovic, Chem. - Eur. J. 2018, 24, 14768; M. Xemard, M. Cordier, F. Molton, C. Duboc, B. Le Guennic, O. Maury, O. Cador and G. Nocton, Inorg. Chem. 2019, 58, 2872; L. Maxwell, M. Amoza and E. Ruiz, Inorg. Chem. 2018, 57, 13225; S. Arndt, T. P. Spaniola and J. Okuda, Chem. Commun., 2002, 896.

25 L. Ungur, M. Thewissen, J. P. Costes, W. Wernsdorfer and L. F. Chibotaru, Inorg. Chem., 2013, 52, 6328.

26 L. Gagliardi, R. Lindh and G. Karlstrom, J. Chem. Phys., 2004, 121, 4494. 